\title{
Politeness research: Key trajectories and their applicability in intercultural communication
}

\author{
Silvie Válková (Olomouc)
}

\begin{abstract}
With the plethora of studies on politeness in general and linguistic politeness in particular, it is difficult for those who want to apply the theoretical findings to authentic language data, to find a roadmap to theoretical framework on which to base the data processing and achieve relevant results. The pre-requisite for such objectives is the familiarity with the existing politeness theories of which to choose with a particular aim in mind, but since there are so many, also the knowledge of their potential taxonomies and the pros and cons of such taxonomies when applied to overt language manifestations of politeness (e.g. in addressing or apologizing). Consequently, the multiple aim of this study is to survey the approaches to the concept of politeness and its layering, outline the taxonomies of various approaches to politeness, and discuss the ways of their applicability (based on my hands-on experience with overt language manifestations of social deixis in addressing and strategies of apologizing). In the application section, the importance of a dynamic, context-sensitive approach to language data is advocated, followed by proposed changes in speech act taxonomies. The conclusion then sums up possible perspectives in intercultural communication which remain a challenge to new insights into politeness research and ELT methodology.
\end{abstract}

\section{$1 \quad$ Introduction}

Politeness, understood as a common-sense notion or a lay concept (Watts 1992), is an old phenomenon, probably as old as the human race itself. It finds its way of manifestation at various levels of human interaction. For some people social behaviour and the way of speaking used to be inseparable, so it was difficult to keep apart the perception of politeness as a kind of social behaviour and its language manifestation, referred to as linguistic etiquette. This is recoverable from various booklets focusing on social etiquette, e. g. How to shine in society published in Glasgow as early as in the $19^{\text {th }}$ century or Ladies' Book of Etiquette, and a Manual of Politeness published in 1872. Examples can be found in fiction, too. In Charles Dickens' Little Dorrit we can read the following: “《Papa〉 is a preferable mode of address», observed Mrs. General. ««Father〉 is rather vulgar, my dear. The word 〈Papa〉, besides, gives a pretty form to the lips»" (1857: 624). Politeness was associated with good manners and formed an important socialization practice. Language seems to have functioned as a subtle but principal way of defining one's social position or having it defined by others. 
As a technical term, however, politeness has been established relatively recently. By its multifaceted nature, the phenomenon of politeness pervades basically all activities which involve contact among people, and as such it is studied by a number of social sciences, e. g. anthropology, applied linguistics, ethnography, psychology, and of course also linguistics. If asked to explain the term politeness, no matter how common it is and how frequently we use it, I think people would face difficulties and see how slippery and elusive it is since it is open to a significant degree of individual variability (hence my preference for scalarity of the term as opposed to binarity - the traditional opposites polite-impolite are seen as various degrees on the scale from polite to impolite, also including overpoliteness and underpoliteness). And it is exactly this variability which needs to be overcome when elevating politeness to the status of a scientific term in various models of politeness theory. Thus we distinguish two subtypes of politeness, which are separable for research purposes but operate in a complex interplay, known as "politeness 1" (in Eelen's [2001: 32] terms), i. e. politeness as an everyday concept, and "politeness 2", interpreted as a scientific conceptualization of the social phenomenon of politeness.

The key notions from this brief introduction that will be echoed in my paper at various places are the multifaceted nature of politeness and the consequent need for an interdisciplinary approach as amplified by Urbanová's (1998: 12) stance that politeness is a social as well as linguistic phenomenon and as such it cannot be measured in "solely in linguistic terms".

My strategy in surveying both the approach to the concept of politeness and the variety of the existing theoretical frameworks will be selective, showing one of the possible ways streaming to applicability in scientific research in one language, in cross-language perspective, and also foreign language teaching. It should also be noted here that my interest is in the politeness pole of the spectrum, though the research into impoliteness has gained in importance in the last few decades (e. g. Culpeper 2009; Bousfield/Locher 2008; Ferenčík 2011). Impolite behaviour is mostly perceived as marked and also violating the norm, however, in some contexts (e. g. army training), it is expected. It is practically impossible to classify impoliteness strategies, and no maxims can be formulated to prevent impoliteness or possible conflict.

\section{The definition of linguistic politeness}

For any research, it is crucial to make the object of the study clear and unambiguous. Politeness, in spite of several decades of research attempting to define it, however, still remains without a single definition that would be comprehensive and consensually accepted. The theoreticians have not always distinguished between the commonsensical notion of politeness and its scientific conceptualization, and the word itself has a number of different denotations and connotations. Instead of listing various definitions, I have opted for my colleague's classification of definitions into four major orientations to politeness according to the prevailing focus they make on independence or involvement aspects of interpersonal communication (Ferenčík 2011: 28). 
a) Avoidance-based conceptualizations

These associate polite behaviour primarily with not doing actions that would somehow damage or infringe upon another person's face, or not doing a negative face-oriented action; and see the justification of polite behaviour in the need to avoid conflict, eliminate aggression or prevent possible friction and/or secure frictionless or smooth communication. An example of such conceptualization can be Lakoff's (1975: 64; emphasis not in the original) definition:

"Politeness is developed by societies in order to reduce friction in personal interaction".

b) Involvement-based conceptualizations

Here politeness is seen as a demonstration for others, as being associated with faceenhancing effects of interactants' actions with a positive impact on interpersonal relations. The definitions reflecting such conceptualizations demonstrate one's orientation towards interpersonal supportiveness as in Sifianou (1992: 86; emphasis not in the original):

Politeness is "the set of social values which instructs interactants to consider each other by satisfying shared expectations".

c) Equilibrium-based definitions

Definitions belonging to this group try to balance both types of needs of a social persona (connection and independence), they subsume the characteristic features of both avoidance-based and involvement-based conceptualizations.

I would include my own definition of politeness (presented in the 2004 monograph) under this heading since I consider both the avoidance of face-threatening acts and the interpersonal supportiveness equally important. In my view politeness is more than just neutral or acceptable behaviour; and similarly to the multifaceted nature of politeness, my definition is also multifaceted, as it is a network of parameters. Thus linguistic politeness characteristics may be more appropriate here than the term definition.

"Linguistic politeness is a partly routinized and partly creative language manifestation of social values, finding its way of reflection at various levels of language representation (phonic, grammatical, lexical, textual, etc.) and reflecting interactional strategies by which interactants signal their interpersonal supportiveness, i. e. their intention to consider each other and satisfy shared expectations about cultural and situational assumptions in order to avoid or at least soften face-threatening acts, to create happy conditions for interaction and to avoid losing one's face" (Válková 2004: 38; emphasis not in the original).

d) Appropriateness-based approaches

In this perspective politeness is seen as appropriate, acceptable or expected behaviour with regard to an existing norm or to others' expectations. According to Meier " (1995: 387; emphasis not in the original):

"Politeness is ...doing what is socially acceptable. 


\section{$3 \quad$ Politeness theories}

The variety of definitions is expectedly reflected in the variety of theoretical frameworks, as apparent from the publication "Bibliography on Linguistic Politeness" (DuFon et al. 1994) published in Journal of Pragmatics on 51 pages, listing nearly 1,000 references to various publications. Watts (2003) announces that he has a bibliography of approximately twelve hundred titles on politeness. Since then the number of publications must have grown exponentially.

There have been systematic attempts at unifying both the content of the notion of politeness and theoretical models that describe it. In 1998, The Linguistic Politeness Research Group was established in order to bring together researchers working on the analysis of linguistic politeness and impoliteness. Since 2005 The Journal of Politeness Research has been published, and special conferences and meetings have been organized in which researchers can share their interest in politeness. The journal also strengthens and widens the existing crosscultural and intercultural politeness research by encouraging new contributions from lesserstudied cultures and languages.

Before getting to the overview of politeness theories, I would like to amplify that before the first systematic studies on politeness, we can trace the source of inspiration for the study of politeness in the ordinary-language philosophy as represented by Paul Grice's (1975) "Logic and Conversation" and in Erving Goffman's notion of "face" (1955) in "On Face Work". Since there is hardly a linguist who does not refer to the two in this field of research, the Grice's Co-operative Principle and Goffman's face will be taken for granted here, but both the theories will be echoed in the present paper at respective places.

Classifying existing theoretical approaches to politeness is not an easy task as apparent from the previous attempts (e.g. Kasper 1990; Fraser 1990; Eelen 2001). My proposed overview subsumes Fraser's (1990) taxonomy of politeness theories, Eelen's (2001) "core" theories (partly overlapping with Fraser) - and Leech's (2014) overview of theories or models of politeness. In agreement with Leech (2014: 55), I would like to stress the fact that "these models are hardly in conflict; they all share common ground, and each seems to add something to the overall picture". I should repeat that my strategy in surveying the models of politeness is selective, as it is not possible to enumerate all of them, nor is it possible to explore the selected ones in the same depth, since their influence on politeness research differs.

For the purposes of my paper, one of the most inspiring contributions to the already existing surveys was a chapter in the book on Power and Politeness in Action: Disagreement in Oral Communication, by Locher (2004). After advocating the need to study the interface of power and politeness, which in her view is a "challenging field of investigation for linguists as both the concepts are not limited to a specific linguistic input, but can be realized or implied with virtually any linguistic form" (ibd.: 159), the author critically surveys the achievements in politeness theories over roughly the last twenty years. She recollects Fraser's (1990) four main areas of research in politeness (the social-norm view, conversation maxim view, facesaving view, and the conversational-contract view), reminds the readers of the sound names within each of the areas and considers the applicability of the discussed approaches and their modifications over time. Her critical remarks, based on her own attempts at applying the existing politeness theories to authentic language data, are as relevant and inspiring as her con- 
clusion that Leech's (2004: 65) approach is too theoretical to apply to real language data, or that the maxims are not suited to capture politeness universally but only culture-specifically. Following Watts (1992) and Kasper (1990), Locher (2004: 89) sees politeness as "conscious, marked behavior", which always has to be appropriate.

A survey of politeness theories going deeper into the history and finding evident traces in the $15^{\text {th }}$ century, is in Shahrokhi and Bidabadi's (2013) study, which, echoing Locher's (2004) survey and her discussion, attempts to outline what the authors call future orientation. The main proposal is to reconsider the notion of universality of politeness manifestations by admitting the existence of two layers of politeness: inter-cultural and intra-cultural. The authors argue in their conclusion that "the consideration of polite interaction among people coming from different cultural background calls for a universal intercultural framework shared globally" (ibd.: 25).

My decision-making priorities result in the following list of theoretical modelling:

- The social norm view (Ide 1989; Blum-Kulka 1985; Gu 1990);

- The conversation-maxim view (Lakoff 1973; Leech 1983);

- The conversation-contract view (Fraser/Nolen 1981);

- The face-saving view (Brown/Levinson 1978; Arndt/Janney 1985; Spencer-Oatey 2000; Scollon/Scollon 2001);

- Politic behaviour view (Watts 1989, 2003);

- The frame-based approach (Aijmer 1996; Terkourafi 1999);

- $\quad$ Leech's approach - revised (2014).

\subsection{The social norm view}

According to Fraser (1990: 220) "the social norm view of politeness assumes that each society has a particular set of social norms consisting of more or less explicit rules that prescribe a certain behavior, a state of affairs, or a way of thinking in a context". One of the first linguists to apply this view in the study of politeness phenomena was Sachiko Ide (1989), who focused on Japanese society. According to some researchers (e. g. Watts, Ide), the social norm view is related to a type of politeness called discernment or wakimae. This, according to Ide, is the practice of polite behaviour according to social conventions; it is helpful in order to have a friction free communication which runs smoothly (unlike "volitional" politeness, described by Brown and Levinson, which is motivated by individuals' wants). Eelen equals discernment with politeness 1 (i. e. everyday concept). He states that in Ide's theorizing there is (implicit) awareness of politeness 1 - politeness 2 distinction, but on closer inspection it appears that this awareness remains superficial, as it is not strictly maintained and its consequences are not fully taken into account.

Similarly to Ide, common sense notions of politeness in different cultures were studied by Blum-Kulka (1985) and Gu (1990). Shoshana Blum-Kulka carried out research among Israeli families; they were probed for their notions of politeness and asked for their opinions about its meaning within family interaction and within Israeli culture in general. Together with her co-researchers (Juliana House and Gabriele Kasper) in the project The Cross-Cultural speech Act Realization Project (CCSARP) she developed careful and productive methodology of 
collecting and analysing speech-act data (requests and apologies). Using the method of discourse completion test (DCTs), the team collected data from seven cultures/languages and compared them in order to arrive at conclusions about strategies used, and their relative frequency. One of the most important theoretical and descriptive outcomes of the project is the recognition that speech acts should not be equated with single utterances (as in Austin Searle tradition); in real life speech acts are often manifested in a sequence of utterances containing various elaborations of the main illocution. This finding has influenced my view on speech acts preferably referred to in my approach as speech act sets; in Leech's (2014) terminology, these would be called "speech events". The applicability of this view will be shown later on some corpus examples (see part 5.2).

Yueguo Gu's (1990) approach is built on a culture-specific notion of politeness in Modern Chinese. His notion of politeness is based on Leech's (1983) view (see below), and consists of a number of maxims, with the addition of an explicitly moral component: the maxims are moralized, socially sanctionable norms. The behaviour that follows the maxims is interpreted in terms of politeness, while the behaviour that abides the maxims results in impoliteness.

\subsection{The conversational-maxim view}

The model relies on Grice's (1975) Cooperative Principle (henceforth CP) and the maxims of conversation. The $\mathrm{CP}$, when simplified, tells speakers that they should say what they have to say, when they have to say it, and the way they have to say it. The maxims are quality (i.e. do not say what you believe is false), quantity (i. e. be as informative as possible), relevance (i. e. be relevant), and manner (i. e. be brief, orderly, avoid ambiguity). In communication, it is assumed that these guidelines are shared by all participants; however, violation of these maxims is quite frequent, too. This can be explained by observing some other (aesthetic, social, moral) maxims, one of which is "be polite" (Grice 1975: 47). Although Grice did not expand on this maxim himself, he became an inspiration for other researchers, the first of them being Robin Tolmach Lakoff. She was denoted by Eelen (2001: 2) as "the mother of politeness theory". She integrated Grice's maxims within her own taxonomy which consisted of two basic rules: "be clear" and "be polite" (she refers to them as rules "of a special kind" [Lakoff 1973: 296]). Both belong to the pragmatic competence (pragmatic well-formedness of utterances). Compare her model from (ibd.: 297; emphasis not in the original):

\section{Pragmatic Competence}

Be clear

Rules of conversation $(=\mathrm{CP})$

1. Quality

2. Quantity

3. Relevance

4. Manner
Be polite

Rules of politeness

1. Don't impose

2. Give options

3. Make A feel good - be friendly

Later, in 1975, Lakoff (1975: 65) reformulated the rule of politeness:

1. Formality: keep aloof

2. Deference: give options

3. Camaraderie: show sympathy 
Similarly to Grice, her theory has both earned criticism and initiated valuable research. Sifianou (1992: 21) stated that even the modified version does not reflect the fact that politeness is broader and more complex than the sum of these rules, and cannot be captured in its integrity by any number of rules.

Geoffrey Leech (1983) also presents a theory based on the conversational maxim view. His Politeness Principle (henceforth PP), similarly to Lakoff, is co-ordinated to the CP (unlike Brown and Levinson who give the PP a secondary status - see below). Leech also adopts Halliday's concept of the functions of language (i. e. ideational, interpersonal, and textual) although he interprets them differently - ideational function as grammar, interpersonal and textual functions as pragmatics. The PP in Leech's model falls under interpersonal rhetoric together with Grice's CP (which he adopts without changes) and the Irony Principle (henceforth IP). The PP and CP interact with each other and often lead to a conflict in which the speaker must decide which of the two to sacrifice. Leech establishes a set of maxims, each with two sub-maxims, which are nowadays almost taken for granted by researchers in the field.

Together with the maxims, there are also associated sets of pragmatic scales (i. e. cost-benefit, optionality, indirectness, authority and social distance scales). In Leech's view maxims, scales, and also situations interact, which offers interlocutors various resources for politenessoriented conduct. This original framework received criticism for potentially infinite number of principles and maxims (Brown/Levinson 1987; Fraser 1990).

\subsection{The conversational-contract view}

This politeness model is represented by Bruce Fraser and William Nolen. Conversational contract (henceforth CC) is understood as a set of rights and obligations followed and observed by participants in interaction. This set, however, is not fixed and there is always a possibility for participants to change the rights and obligations on which they have agreed at the beginning of the interaction. The CC view is similar to the above mentioned Social Norm view (see 3.1) in that politeness involves conforming to socially agreed codes of good behaviour. It is, however, different from the Social Norm view because in the $\mathrm{CC}$ view the rights and obligations are not fixed but negotiable. I will show the applicability below (part 5.1) on an example of situation-bound negotiation in addressing.

"Being polite constitutes operating within the then-current terms and conditions of the CC" (Fraser 1990: 233). Politeness is seen as a normal or default state, noticeable is its absence, i. e. impoliteness. Socio-cultural norms and patterns are the determinant factors in applying $\mathrm{CC}$ model of politeness, which makes the model universally applicable.

\subsection{The face-saving view}

The term "face" was first defined by Goffman (1967: 5) as "the positive social value a person effectively claims for himself by the line others assume he has taken during a particular contact". In his conception face is only temporary, rooted in one particular communicative situation. According to Penelope Brown and Stephen C. Levinson face is a constant attribute of each person. Their theory, despite all the criticism, remains the most influential up to date. It is based on a Model Person (henceforth MP), a fluent speaker of a natural language who is equipped with two special characteristics, namely "rationality" (the mode of reasoning) and 
"face" (the public self-image that every member of society wants to claim for himself). Face has two aspects - "negative" (the desire to act unimpeded by others) and "positive" (the desire to be approved of in certain respects). Brown and Levinson claim that face must be constantly attended to in communication, so before any interaction speakers should take into consideration the social distance between speaker and hearer, relative power of hearer over speaker, and also the dangerousness of an act within a given culture. This should help speaker select an adequate face-saving strategy (from performing an act unequivocally through being indirect to rather not saying anything) before selecting adequate linguistic means. In connection with negative and positive face, Brown and Levinson suggest various negative and positive politeness strategies (e.g. negative: indirectness, using hedges or questions, apologizing; positive: complimenting, making offers and promises). Dividing politeness strategies into negative and positive may suggest that they appear separately, and this is also what Brown and Levinson claimed. Language data, however, prove the opposite and in many situations we can find both strategies following one another, e. g.: "Goodness, you cut your hair. How lovely! ... By the way, I came to borrow some flour" (Simpson 1997: 162).

Brown and Levinson's universality of the concept of face was criticised for insufficient data (from only three languages) which were rather decontextualized, not authentic; the criticism was also related to the Anglocentric bias and neglect of the dynamic aspects of social language use. In spite of this, their theory influenced other researchers, and there is hardly a publication on linguistic politeness which does not refer to Brown and Levinson's Politeness.

The face-saving view created basis for other elaborations, namely those by Horst Arndt and Richard Janney (supportive face-work and interpersonal politeness), Helen Spencer-Oatey (view of rapport management), and Ron Scollon and Suzanne Wong Scollon (intercultural communication).

Arndt and Janney (1985) in their Supportive Face-work and Interpersonal Politeness see politeness as interpersonal supportiveness consisting of supportive face-work strategies (both verbal and non-verbal) that express positive or negative feelings without threatening the interlocutors emotionally. In their view supportiveness is not a function of what to say but how to say it; important is their focus on interlocutors. They stress the role of the interpreter who decides how a given style is interpreted, while style itself cannot be polite.

Spencer-Oatey's (2000) Rapport Management differs from Brown and Levinson's original framework in excluding the notion of negative face and introducing group identity instead. "Rapport management" means managing harmony and disharmony in social interaction, while communication is oriented towards creating positive interpersonal relationships. Later (2008) the author characterizes the face as involving three levels of representation: the personal or individual level, the relational level, and the collective level. Each of these levels is associated with different face sensitivities (e. g. you can disparage one's person, their parentage, or their nationality).

Scollon and Scollon's (2001) Intercultural Communication introduces the terms "involvement" and "independence" instead of positive and negative face. The term involvement refers to group needs; independence refers to the individual nature of interlocutors. The authors stress the fact that different groups have different needs, which makes the model suitable for studies adopting a cross-cultural approach. 


\subsection{Politic behaviour view}

Richard Watts, the representative of this view, belongs to the group of linguists who explicitly distinguish the common sense or lay notion of politeness from the theoretical notion (referred to as first-order and second-order politeness, in Eelen's, nowadays more frequent terminology politeness 1 and politeness 2).

Politeness, in Watts' (1989: 135) understanding, is subsumed under “politic behaviour", i. e. behaviour which is "directed towards the goal of establishing and/or maintaining in a state of equilibrium the personal relationships between individuals". Politic behaviour is unmarked, neutral, and taken for granted, while politeness is a marked deviation, an "explicitly marked, conventionally interpretable subset of politic verbal behaviour responsible for the smooth functioning of socio-communicative interaction“ (ibd.: 136). In subsequent elaborations, Watts distinguishes between two types of deviation - positive or polite and negative or nonpolitic deviation. He develops the theory of polite and politic behaviour as being a part of a continuum of relational work carried out in any verbal interaction and according to him it is the participants of the interaction who evaluate certain forms of behaviour as polite or impolite, which can be different from culture to culture. For this view, however, he was criticized (e. g. Terkourafi, Leech) because the line between politic and polite is arbitrary, based on the intuition of participants.

\subsection{The frame-based approach}

This approach was not introduced in Fraser's classification, which was the basis of my taxonomy of politeness theories, but in Leech's (2014) latest monograph. It is represented by Karin Aijmer (1996) and Marina Terkourafi (1999), who approach politeness "as culture-specific ready-made patterns" (Leech 2014: 38). The term "pattern/frame" itself was used as early as 1975 by Minsky (1975: 212) to refer to "data-structure for presenting a stereotyped situation". Frames are construed in individuals during the socialization process and although they are universal, their concrete realization is dependent on the culture as individuals generalize their experience in certain contexts.

The concept of frame has been worked out in some detail by Aijmer, in her book Conversational Routines in English (1996), on the basis of an analysis of speech act frames in the London-Lund Corpus of Spoken English. This, in my opinion, may be quite useful, especially in second or foreign language learning where students (especially those on lower levels) rely on these routines rather than their own creativity in varieties of speech events. An example of such a frame can be the way how to let passengers know that a bus is out of service. In English, this institutional apology is usually worded as if it were a personal apology of the driver, i. e. Sorry, I'm out of service. In Czech, however, a more straightforward, depersonalised language manifestation is more common, i. e. Mimo provoz. (the English equivalent would be 'out of service'). The knowledge of these frames and their language manifestations in the respective languages (mother tongue and foreign language) would allow learners avoid pragmatic mistakes which are considered by native speakers more serious than grammatical mistakes. 


\subsection{Leech's approach - revised}

In his latest monograph, Geoffrey Leech (2014: 43) characterizes the current view on politeness as postmodernist. This view is rather sceptical towards abstract and theoretical conceptions of politeness, towards its stable interpretation, and also towards any attempts to make politeness research more objective. Leech states that in the views of previous researchers (e. g. Brown/Levinson, Lakoff), politeness functions primarily as a means of maintaining face and social concord. In contrast, the current view on politeness places it in the context of social struggle and sees it as a tool for maintaining hegemony in the hands of the powerful.

Leech responds to the criticism of his earlier work and reformulates the model presented in his previous book (1983). One of the things that he (similarly to Brown and Levinson) has been criticised for was the Western bias of his model, which would be inappropriate to the collectivism of Eastern cultures. He still argues that any model of politeness should be generalizable to various cultures, and the two different wants (i. e. Western individualism and Eastern collectivism) are not in contradiction but rather that "they are positions on a scale" (2014: 83). In his new approach, however, when exemplifying individual maxims, Eastern languages (e. g. Chinese, Japanese) are used together with English.

In the 1983 model (see 3.2) six maxims of politeness were introduced. In his new model, Leech (2014: 91) presents ten maxims which can be conceived as a more specific realization of the General Strategy of Politeness (henceforth GSP). In order to be polite, S(peaker) expresses or implies meanings that associate a favourable value with what pertains to O(thers) or associates an unfavourable value with what pertains to $\mathrm{S}$. The list of maxims according to Leech is not complete; the following are the most observable.

M1 - Generosity maxim (give a high value to O's wants)

M2 - Tact maxim (give a low value to S's wants)

M3 - Approbation maxim (give a high value to O's qualities)

M4 - Modesty maxim (give a low value to S's qualities)

M5 - Obligation of $\mathrm{S}$ to $\mathrm{O}$ maxim (give a high value to $\mathrm{S}$ 's obligation to $\mathrm{O}$ )

M6 - Obligation of $\mathrm{O}$ to $\mathrm{S}$ maxim (give a low value to O's obligation to $\mathrm{S}$ )

M7 - Agreement maxim (give a high value to O's opinions)

M8 - Opinion-reticence maxim (give a low value to S's opinions)

M9 - Sympathy maxim (give a high value to O's feelings)

M10 - Feeling-reticence maxim (give a low value to S's feelings)

What is also important to state is that the above-listed maxims are not separate, independent constraints; they are instances of the operation of GSP. There is also cultural variability in the power of individual maxims.

In the research part of the book, based on two corpora, i. e. the British National Corpus and the Longman Corpus of Spoken American English, various "politeness-sensitive" speech events are introduced, e.g. apologies, offers, compliments, thanks and responses to thanks. The novelty in the approach to these speech events in introducing various factors which define the nature of the events, Leech calls these factors "territories" and in the "topography of the territories" the factors and characteristic features are listed (e. g. politeness characteristics - whether pos- or neg-politeness event; parts of the event - head and possible satellite events; 
formulae and expressions used; internal and external modifications, etc.). This, in my opinion, would be an invaluable source of information for teachers of foreign languages. If the territories were clearly defined in individual languages, this would offer information about various polite speech events and it would also allow comparison with the mother tongue of learners, which would help to avoid negative transfer.

\section{$4 \quad$ Prospects for the future}

Though it is difficult to predict which results of the diffused spectrum of recent research will be capable of generating the mechanisms on which to base innovative approaches to linguistic politeness, we can trace some of the directions in innovative processes which reflect the crucial role of language interaction in communicative manoeuvring across languages and across the globalized world.

Creeping from the relatively recent studies on linguistic politeness are some tendencies reflecting various facets of the current need to cope with:

(1) new communication technologies and the ways interactants negotiate the interpersonal component of language use in various computer-mediated settings, both synchronic (chats) and asynchronic (blogs);

(2) the necessity of a more systematic interdisciplinary approach to politeness, in which the very notion of "politeness" is looked upon as being interwoven into the network of such sociolinguistic notions as "facework" and "identity" (with a postmodernist understanding of the concept of identity as "the social positioning of self and other" (Bucholtz/Hall 2005: 586);

(3) the globalizing world and the culture-sensitive interpretation of cognitive processes underlying overt language manifestation of politeness in difference socio-cultural settings and

(4) discursive models that engage with both politeness and impoliteness Relatively recent are also the tendencies to integrate theoretical findings on politeness into foreign language teaching methodologies and second language acquisition in more systemic, computer mediated ways (cf. for example the system POLLY, i. e. Politeness for Language Learning, proposed by Gupta et al. [2007], which combines a spoken language generator with artificial intelligence planner to apply Brown and Levinson's theory of politeness in learning English as a second language).

Below are some samples of the above mentioned tendencies.

The study by Danescu-Niculescu-Mizil et al. (2013) is a proposal of a computational framework for identifying linguistic politeness, as manifested in requests. Using a corpus of requests annotated for politeness, the authors have constructed a "classifier" sensitive to such components of politeness theory as indirectness, deference, impersonalization and modality. The classifier is said to allow the researchers to study the interaction between the politeness markers and context, but also the relationship between politeness and social power (with an emergent negative correlation between politeness and power showing that users of higher social reputation are less polite than those at the bottom of the imaginary scale). Moreover, 
the classifier can be used in analysing gender and community variation in politeness manifestations.

Ogiermann's (2009) study on requests is an inspiring example of cross-language analysis of speech act manifestation in two Slavic and two Germanic languages, focusing both on requests and their direct and indirect perception. The research is based on a dynamic, contextsensitive approach, taking into view various culture specific syntactic and lexical softeners, avoiding or at least reducing face threatening acts. The requests, elicited by means of discourse completion task as responses to frequently used request scenarios, were then subcategorized into direct and indirect with the finding that while direct responses were central in Russian and Polish, indirect requests were more frequent in English and German. The author claims that the findings are applicable to other languages in studying the proportion between conventional indirectness and directness in the target languages.

The projection of politeness into a larger framework exploring the links between identity, face and politeness has still remained a challenge, though a thought-provoking contribution to the field was published in 2008. In the book section, entitled Relational work, politeness and identity construction, Locher based her analysis on a postmodernist understanding of the concept of identity, and advocates the idea that the research of the social positioning of self and other can be fruitfully combined with the research of politeness. The study is innovative in discussing the already identified approaches to politeness with identity construction in mind, reminding one of the Halliday's (1978) conception of language as social semiotic and the role of his interpersonal component in our everyday encounters. Preceding Locher's publication was, for example, an identity- and interaction-oriented study by Bucholtz and Hall (2005).

Since the aim of the samples is only illustrative, I will close this section with the optimistic finding that politeness is perceived in most of the recent studies as a scalar notion ranging from politeness to impoliteness, with a context-sensitive interpretation of the positioning within the scale due to various intensifying or downgrading contextual factors. More relevant results in politeness theory have been achieved with integrated models, considering politeness as a part of the integrated framework based on the links between politeness, identity, and face.

\section{$5 \quad$ My theoretical approach}

My main interest is in what Leech (2014: 14) calls "contrastive pragmalinguistics" which analyses and compares the linguistic resources for politeness available, and their use in different languages, namely English and Czech. Before I introduce the practical part of my research, let me introduce the theoretical framework I apply.

My understanding of linguistic politeness nowadays, after more than ten years since I published the monograph, does not differ significantly from the definition or rather the characteristics that I introduced (see Part 2). Apart from the features that I consider important in connection with defining the object of study, I would like to present the theoretical foundations my view on politeness resonates with and specify the theoretical framework applied in analysing language data.

The theoretical framework applied in my research is rooted in functional and systemic grammar, as advocated by the Prague school scholars, their followers and linguists working within 
a similar functional framework (e. g. M. A. K. Halliday) where language is intrinsically regarded as a vehicle of communicative interaction and as such is said to have a strongly pragmatic orientation. The analysis of corpus-based data brings me to the representation of "actual system" (utterances) rather than to the "virtual system" (sentences). In terms of Halliday's (1973) metafunctions, my interest is in the interpersonal metafunction, although it is difficult to separate it from the other metafunctions, as in actual usage both the ideational and interpersonal metafunctions naturally form a text. My approach also takes into consideration the sociolinguistic perspective as represented e. g. by Halliday's (1978: 12) conception of "man as a social man" and "language as social semiotics", when claiming that politeness is a social as well as linguistic phenomenon. Politeness, in my view, is not a static logical concept but a "dynamic interpersonal activity" (Janney/Arndt 1992: 22), reciprocal negotiation between the speaker and hearer. When working with corpus-based data I realized that politeness strategies are not always self-evident, politeness is not a real fact, and it should not be taken for granted that when certain expressions are used, the associated polite intentions are recognized. Frequently, the strategy is recognized as polite only when understood as such by the hearer (e.g. an example of a compliment response from the British National Corpus [BNC(AEG(409))]: Was this to be regarded as a compliment or a criticism?). Another thing is that definitions of politeness prevail while impoliteness is intrinsically understood as the opposite, i. e. the absence of politeness, missing thus the neutral or appropriate behavior (in Watts' [2003: 19]) terminology "politic behavior"). Politeness and impoliteness in my view are scalar notions, leaving space to context-sensitive interpretation.

In the following part I would like to illustrate some of the approaches introduced in the theoretical overview in practical application on language data.

\section{$6 \quad$ Practical part - application}

\subsection{Context-sensitive approach: forms of address}

In this part I would like to show the importance of a dynamic approach to language data on selected samples of the analysis of address forms. In my view mere lists and quantifications (static approach) can sometimes lead to simplified if not misleading results and often do not show the interplay of other factors that influence our communication. This, however, does not mean that either approach is more important. Quantifications can show us some tendencies in usage, as illustrated for example in Leech (2014: 294) who in the chapter on "Politeness and the History of English" mentions the tendency toward increasing democratization (i. e. reduction of overt markers of power asymmetry). This, in terms of addressing, means decreasing use of honorifics, particularly Sir, Madam, Mr., Mrs. and Miss over the last one hundred years. Between 1961 and 1991, in an American English corpus study, the frequency of use of $M r$. dropped by approximately a third, while the frequencies of Mrs. and Miss each declined by more than two thirds. There was a similar drop in British English. These statistics, however, do not show us how and when to use appropriate forms of address.

The examples used in this part are taken from the corpus Ferenč́k (1998) used in his dissertation. I was looking for a type of spoken language data, situations where people are somehow forced to address each other, be polite and at the same time be sensitive to the context. These 
conditions were met in Irv Homer Talk Show, a live American phone-in talk show, mostly dyadic, with Irv Homer as a moderator - and callers. Sometimes occasional studio-guests are invited to participate in the discussion on issue-oriented topics of general interest.

The following examples will show the forms of address as a result of negotiation between the interlocutors during the process of interaction. They show that the model of social deixis signalled by the first moves in communication need not necessarily be the model the communication ends up with. The reasons for the change might vary - in the chosen examples it will be the role of immediate context (Example 1) and the importance of the content of the message (Example 2), as emergent from the following skeleton of exchanges.

Example 1

Call I/10 (= Show I, call 10)

$1 \mathrm{M}$ (the number stands for "exchange one", $\mathrm{M}=$ Moderator, $\mathrm{C}=$ Caller)

1M hello Frank

2C ...good afternoon Irv

3M ...good afternoon, sir

$5 \mathrm{M} \quad$...yes sir...

In this skeleton of conversation between the moderator and caller, we can see that an important decision-making factor in the interpretation of the semantics of power and solidarity (as reflected in addressing) is the immediate contextual embedding, as in the greeting + address sequences, in which the choice of the greeting can move the address towards one or the other side of the scale of solidarity/power semantics.

The first offer of solidarity by the M(oderator), (hello + T-exchange Frank) is only partly reciprocated by the $\mathrm{C}$ (aller) in (good afternoon, Irv). Accordingly, the $\mathrm{M}$, sensitive to the suggestion of a partial distance (hello $>$ good afternoon), reciprocates by total distance (good afternoon, sir) and follows the established (negotiated) pattern of addressing, as apparent from $5 \mathrm{M}($ sir $)$.

Example 2

Call III/3

$(\mathrm{M}=$ Moderator, $\mathrm{C}=$ Caller: Peter, male $)$

$1 \mathrm{M}$ hello Peter

2C Irv please don't get out of this business, you're too important

3M I gotta get out of

$4 \mathrm{M}$ this

5C I absolutely agree with you. I have two comments, one about Claude Louis and one about the malls in America and I wanted to say I served in

$6 \mathrm{M}$ yes sir

$5 \mathrm{C}$ Vietnam and I was part of the Vietnam Veterans against the War when I came back and you're absolutely right when your your comments and you've said it for years about what's torn this country apart so I think that the

$7 \mathrm{M} \quad$ but if you listen to the Democrat

5b C community should acknowledge you for all your clear reporting 
8M have you listened to these yahoo Republicans and Democrats and yahoo Conservatives it was your fault because you were supposed to go over there? without questions no declaration of war and you were supposed to die Peter

9C oh I did go over there? and fortunately I didn't die? but many of others that I know did but I woke up while I was there Irv and I decided this is

$10 \mathrm{M}$ and this moron

$11 \mathrm{M}$ and this moron this moron Ronald Reagan says it was a what did he say it was admirable venture? or something? why the hell didn't he go

12C right

13C That's right but I wanted to also say I watched you on TV yesterday eh with Claude Lewis? when you were attempting to eh clarify in states and facts

14M yes sir

This skeleton of the call can demonstrate how the content of the message can influence the form of the address. The initial exchanges are symmetrical up to the moment, when the key message, i. e. I served in Vietnam is introduced. After this statement, M switches to Vexchange (6M) sir - and it is difficult to say whether the prevailing reason is to express sympathy or deference, but most probably a mixture of both. In $8 \mathrm{M}$, however, it is apparently sympathy that causes the change in M's strategy, cf. the switch to FN Peter. When the topic is over, an unexpected switch to V-exchange ( $\operatorname{sir}$ in 14M) closes the call. One of the possible explanations might be that the feeling of deference prevailed, another suggestion might be that there is no air of like-mindedness between them but rather a context-bound tension. The $\mathrm{C}$ is not addressed in the closing part of the call, the $\mathrm{M}$ just thanks for calling, to which there is no reaction by the caller at all.

What was also observable in the dialogues was the activation of two axes - vertical and horizontal, which corresponds with two types of rules suggested by Ervin-Tripp (1972: 240) "alternation rules" and "co-occurrence rules". Alternation rules are said to represent the sociolinguistic equivalent of the paradigmatic axis of linguistics and their role is to control the choice of linguistic elements from the total repertoire that is at language user's disposal. In addressing, for example, the alternation rules are represented by the choice out of such items as

$$
\mid \begin{aligned}
& \text { Madam } \\
& \text { Professor } \\
& \text { Jane } \\
& \text { my dear }
\end{aligned}
$$

which are said to form the address system of the language, and the choice of which is socially determined, thus representing sociolinguistic variables.

Co-occurrence rules, in contrast, are syntagmatic in nature, since they activate the horizontal axis of sequential relationships in such a way that the choice of address, e. g. Jane, implies later uses not only of the same term but also of possible lexical replacements of the type my friend, etc., colloquial expressions, less careful pronunciation, etc. On the other hand, the choice of Professor, for example, implies later uses of whimperatives (also referred to as "dressed imperatives", i. e. orders modified into softened requests, as in Would you tell me the 
difference?), choices of standard grammatical structures as well as lexical items, careful pronunciation, etc.

With the above-mentioned examples I hope I have illustrated and amplified the need of a context-sensitive (situation-based) approach to authentic language data and illustrated how corpus data enable us to reveal various socio-pragmatic interpretative clues to overt language manifestations of politeness.

In the following part I would like to advocate some proposed changes in taxonomies (from speech acts to speech act sets/events) and illustrate their applicability.

\subsection{Changes in taxonomies: speech acts - speech act sets/events}

The recognition of speech acts by the philosophers of language (Austin 1962; Searle 1969) contributed to a shift in linguistic thinking in the second half of the $20^{\text {th }}$ century, from a prevailingly prescriptive to a significantly descriptive approach, based on authentic language data of ordinary language use anchored in a situational context. I have already mentioned The Cross-Cultural speech Act Realization Project and the research carried out by Shoshana Blum-Kulka and her co-researchers. One of the most important theoretical and descriptive lessons learned from their project is the recognition that speech acts should not be equated with single utterances (as in Austin - Searle tradition); in real life they are often manifested in a sequence of utterances containing various elaborations of the main illocution. This idea of a speech act set was supported by other linguists, e. g. Murphy and Neu (1996). On the other hand, there are some linguists (e. g. Scollon/Scollon 2001; Leech 2014) who prefer to speak about a speech event if more interlocutors participate in the overt language manifestation of such a set.

Below I will introduce apologies within the theory of speech act sets and discuss the constants and variables in the patterns of their realisations as emergent from the corpus data.

The idea of an apology as a speech act set appeared in Cohen and Olshtain (1981); they found that an apology can comprise one or more components, each of which could be a speech act in its own right (see Table 1).

\begin{tabular}{|l|l|l|l|}
\hline an apology (1) & $\begin{array}{l}\text { acknowledgement of } \\
\text { responsibility (2) }\end{array}$ & $\begin{array}{l}\text { an offer to compen- } \\
\text { sate (3) }\end{array}$ & $\begin{array}{l}\text { a promise of for- } \\
\text { bearance/an expla- } \\
\text { nation (4) }\end{array}$ \\
\hline
\end{tabular}

Table 1: The model of apology as a speech act set 1 (after Cohen/Olshtain 1981: 119)

When exemplified by language data, one of the possible manifestations of an apology as a speech act set can have the following form (based on Tanck 2004: 2):

I'm sorry, (1) / it was my fault. (2) / I'll replace it. (3) / It will never happen again. or It was an accident. (4)

The speech act set approach was elaborated by Blum-Kulka, House, and Kasper (1989) to provide a five-item pattern of apologising composed of the following components: an illocutionary force indicating device (IFID), e.g. I apologise, I'm sorry, Excuse me, etc., followed by an apologetic account, different strategies for expressing responsibility, offers of repair, and a promise of forbearance. 
The following figure may illustrate the concept in a more transparent way:

\begin{tabular}{|l|l|l|l|l|}
\hline IFID (1) & $\begin{array}{l}\text { an apologetic } \\
\text { account (2) }\end{array}$ & $\begin{array}{l}\text { an expression of } \\
\text { responsibility (3) }\end{array}$ & $\begin{array}{l}\text { an offer of re- } \\
\text { pair (4) }\end{array}$ & $\begin{array}{l}\text { a promise of for- } \\
\text { bearance (5) }\end{array}$ \\
\hline
\end{tabular}

Table 2: The model of apology as a speech act set 2 (after Blum-Kulka et al. 1989: 20)

The following example is a possible manifestation of the above-mentioned model in Table 2 (based on Blum-Kulka/Olshtain 1984: 207-208):

I'm sorry (1) / I'm so late. (2) / You know me I'm never on time (3) / I'll see what I can do. (4) / This won't happen again. (5)

One of the drawbacks of their model revealed by my corpus-based analysis (see below) is the presupposed regularity of the above-mentioned sequences within the speech act set, which is not supported by natural language data. To illustrate the variability and complexity of natural encounters, I borrowed an example from Fraser (1981) that may serve as a good sample of what I have in mind when speaking about the complexity and also the partial unpredictability of the configurations of speech act sets. It is clear that the individual parts in this example are incompatible with the schema presented in Table 2.

(In this example a mother is talking to her children about an impending divorce.)

I'm sorry. (1) / I know how much it hurts you. (2) / I just have to do it (3) / and you've got to try to understand. (4) / Daddy will still be your father. (5) (Fraser 1981: 266).

When applying the above-mentioned speech act set approach, we can identify the following:

\begin{tabular}{|l|l|l|l|l|}
\hline IFID (1) & event (2) & justification (3) & $\begin{array}{l}\text { request for under- } \\
\text { standing (4) }\end{array}$ & $\begin{array}{l}\text { a soothing } \\
\text { remedy (5) }\end{array}$ \\
\hline
\end{tabular}

Table 3: The model of apology - application of natural language data

In the article "The learning of complex speech act behaviour" Olshtain and Cohen (1990: 47), modified their original model of the speech act set of apology into a five-item pattern which reflects two strategies that are general and hence not liable to contextual constraints (i. e. the explicit expression of an apology, i. e. IFID, and the expression of responsibility). The other three strategies are situation-dependent and much more limited in their usage (i. e. an explanation, an offer of repair, and a promise of forbearance).

\begin{tabular}{|l|l|l|l|l|}
\hline IFID (1) & $\begin{array}{l}\text { an expression of } \\
\text { responsibility (2) }\end{array}$ & $\begin{array}{l}\text { an explana- } \\
\text { tion(3) }\end{array}$ & $\begin{array}{l}\text { an offer of re- } \\
\text { pair (4) }\end{array}$ & $\begin{array}{l}\text { a promise of for- } \\
\text { bearance (5) }\end{array}$ \\
\hline
\end{tabular}

Table 4: The model of apology as a speech act set 3 (Olshtain/Cohen 1990: 47)

In accordance with their finding that "Potentially, the expression of an apology and/or the expression of speaker's responsibility could realize an apology act in any situation" (ibd.: 47), I would suggest that although there are more strategies that make up the speech act set, there is no fixed number of strategies, nor any regularity of the sequences of discrete slots and their expected fillers (see below).

The following examples (excerpted from the book version of A Corpus of English Conversation by Svartvik and Quirk [1980], also referred to as the London-Lund Corpus) show that the five-item pattern matrices would sometimes results in more empty slots than explicit fillers 
(the case of two-item and three-item pattern configurations). Various modifications appear, with some of the slots being identical with the configurations suggested in the abovementioned models but also with other parts that were not taken into consideration and whose presence in the pattern would break the presupposed regularity of the sequences.

I'm terribly sorry (1) / but I shan't be with you until five past ten. (2) (ibd.: 130).

\begin{tabular}{|l|l|}
\hline IFID (1) & $\begin{array}{l}\text { an apologetic } \\
\text { account (2) }\end{array}$ \\
\hline
\end{tabular}

(... and he tried to wave me in) I said no I'm not coming in (1) / I'm sorry. (2) (ibd.: 360).

\begin{tabular}{|l|l|}
\hline $\begin{array}{l}\text { an apologetic } \\
\text { account (1) }\end{array}$ & IFID (2) \\
\hline
\end{tabular}

I'm sorry (1) / about the mess, (2) / how stupid of me. (3) (ibd.: 281).

\begin{tabular}{|l|l|l|}
\hline IFID (1) & $\begin{array}{l}\text { an apologetic } \\
\text { account (2) }\end{array}$ & disarmer (3) \\
\hline
\end{tabular}

I'm very sorry (1) / I cannot teach at the institute. (2) / I will do my best to find someone who can (3) / and I would suggest you do the same. (4) (ibd.: 76).

\begin{tabular}{|l|l|l|l|}
\hline IFID (1) & $\begin{array}{l}\text { an apologetic } \\
\text { account (2) }\end{array}$ & an offer of repair (3) & suggestion (4) \\
\hline
\end{tabular}

I'm sorry (1) / I haven't replied (2) / but I would. I'm going to (3) / because I would like to come. (4) (ibd.: 106).

\begin{tabular}{|l|l|l|l|}
\hline IFID (1) & $\begin{array}{l}\text { an apologetic } \\
\text { account (2) }\end{array}$ & an offer of repair (3) & $\begin{array}{l}\text { explanation (4) } \\
\text { (or reasoning) }\end{array}$ \\
\hline
\end{tabular}

These results confirm that for the corpus-based samples the speech act set status of apologies is more adequate than a single speech act approach, leaving some space for culture- but also situation-bound variables, both qualitative and quantitative (cf. different configurations within the set, as well as partly predictable and partly unpredictable reductions/extensions of the speech act set).

Similarly to the theoretical part, I was also selective in the choice of the application of theoretical findings on language data, but even with this limited possibility I hope to have contributed to the validity of the already shared view that whichever theoretical framework is prioritised, it should always be verified by authentic data easily accessible from a variety of language corpora. Research shows that various communicative situations do not always allow for straightforward and transparent classification of all language phenomena which cannot be forced into various slots or boxes of the theoretical modelling. On the contrary, various communicative situations allow for a variety of language-in-action modifications. These findings correspond with Mathesius' (1982) notion of the potentiality of language phenomena, according to which there are many language devices at language users' disposal, but they need not necessarily be activated in fixed configurations of patterns. Though it might sound commonplace, I feel it necessary to amplify that in real communicative situations the actual language use is the result of a complex interplay of linguistic and extra-linguistic factors. 


\section{$7 \quad$ Conclusion}

Although politeness has been studied for several decades, in accordance with its multifaceted nature, there are still different perspectives from which the horizons of this phenomenon can still be broadened. There are possibilities of new theoretical modelling - either completely new approaches or deriving new ones from the above-mentioned models. From the comparative perspective, I see the potential in mapping territories of politeness-sensitive events in various languages. In the past, foreign language teaching concentrated on "core linguistics" (i.e. phonetics, grammar, etc.). In 1983, Thomas published an influential article "Crosscultural pragmatic failure", suggesting that the nature of pragmatic language learning was considerably different from the learning of grammar. While in grammar we can make errors, in pragmatics we speak rather about failure as there are no prescriptive rules. This pragmatic failure can be more serious than grammatical errors. Learning to communicate successfully (including politely) in a foreign language is above all a matter of linguistic competence and performance, but also a matter of appropriateness, cultural adaptation and accommodation. The knowledge of politeness-sensitive events would enable foreign language learners to reach their communicative goals more easily. There is also the historical perspective, which can show the changes of various politeness phenomena in the course of time (e.g. the abovementioned changes in the forms of address) and which still offers new areas to be researched and perspectives to be applied. This holds true of contrastive pragmalinguistics and intercultural communication.

One way of how to move further, particularly in the field of intercultural communication, is prompted by Leech (2014) and his proposal of several discrete steps by which to create a matrix of prototypical features characterising various politeness-sensitive speech events. The first step would be to identify two basic parts of such events, i. e. a head and possible supporting moves (satellite events). The head, according to Leech, equals to the identifier of the illocutionary force (IFID). The supporting moves refer to other components of the set creating - together with other characteristics (as illustrated by his example of apologies) - the territory, such as compliment, offer, or thanks territories (ibd.: 133). The cross-language and cross-cultural comparison of such territories, based on source and target language matrices, may become the basis for more delicate research of culture-based preferences in (non)ritualised language use, norms of expectations in politeness behaviour, etc.

This leads us to the conclusion that despite the fact that though politeness has been thoroughly researched by many scientists, there are still many facets of its manifestation waiting to be addressed. The need to eliminate possible sources of friction is of great importance, especially now with the increasing number of interactions among people who come from different cultural backgrounds. To enable them to communicate without misjudgements of different communication norms should be the aim of politeness research.

\section{References}

Aijmer, Karin (1996): Conversational routines in English: Convention and creativity. London: Longman.

Arndt, Horst/Janney, Richard (1985): "Politeness revisited: Cross-modal supportive strategies”. International Review of Applied Linguistics in Language Teaching 23/4: 281-300. 
Blum-Kulka, Shoshana/House, Juliane/Kasper Gabriele (eds.) (1989): Cross-cultural Pragmatics: Requests and Apologies. Norwood/NJ: Ablex.

Blum-Kulka, Shoshana/Olshtain Elite (1984): "Requests and Apologies: A Cross-Cultural Study of Speech Act Realization Patterns (CCSARP)". Applied Linguistics 5/3: 196-213.

Bousfield, Derek/Locher, Miriam (eds.) (2008): Impoliteness in Language. Studies on its Interplay with Power in Theory and Practice. Berlin/New York: Mouton de Gruyter.

Brown, Penelope/Levinson, Stephen (1978): "Universals in language usage: Politeness phenomena". In: Goody, Esther N. (ed.): Questions and politeness: Strategies in social interaction. Cambridge, Cambridge University Press: 56-289.

Brown, Penelope/Levinson, Stephen (1987): Politeness, Some Universals in Language Usage. Cambridge: Cambridge University Press.

Bucholz, Marry/Hall, Kira (2005): "Identity and Interaction: A Sociocultural Linguistic Approach”. Discourse Studies 7/4-5: 585-614.

Cohen, Andrew/Olshtain Elite (1981) "Developing a measure of sociocultural competence: The case of apology". Language Learning 31/1: 113-134.

Culpeper, Jonathan (2009): Impoliteness: Using language to cause offence: Full Research Report ESRC End of Award Report, RES-063-27-0015. Swindon: ESRC.

Danescu-Niculescu-Mizil, Cristian et al. (2013): “A Computational Approach to Politeness with Application to Social Factors”. Proceedings of ACL 2013: 250-259.

Dickens, Charles (1857): Little Dorrit. Vol. 2. London: Bradbury and Evans.

DuFon, Margaret A. et al. (1994): "Bibliography on linguistic politeness". Journal of Pragmatics 21: 527-578.

Eelen, Gino (2001): A Critique of Politeness Theories. Manchester: St Jerome.

Ervin-Tripp, Susan M. (1972): "On sociolinguistic rules: Alternation and co-occurrence". In: Gumperz, John J./Hymes, Dell (eds.): Directions in Sociolinguistics. New York, Holt/Rinehart and Winston: 213-250.

Fraser, Bruce/Nolen, William (1981): "The association of defernce with linguistic form". International Journal of the Sociology of Language 27: 93-109.

Fraser, Bruce (1990): "Perspectives on Politeness". Journal of Pragmatics 14: 219-236.

Ferenčík, Milan (2011): Doing (Im)Politeness in the Media. Prešov: Filozofická fakulta Prešovskej univerzity.

Goffman, Ervin (1955): “On face-work: An analysis of ritual elements in social interaction”. Psychiatry: Journal for the Study of Interpersonal Processes 18: 213-231.

Grice, Herbert Paul (1975): "Logic and Conversation". In: Cole, Peter/Morgan, Jerry (eds.): Syntax and semantics 3: Speech acts. New York, Academic Press: 41-58.

$\mathrm{Gu}$, Yeguo (1990): "Politeness phenomena in Modern Chinese". Journal of Pragmatics 14: 237-257.

Gupta, Swati/Walker, Marilyn A./Romano, Daniela M. (2007): "How Rude Are You?: Evaluating Politeness and Affect in Interaction”. In: Paiva, Ana/Prada, Rui/Picard, Rosalind W. (eds.): ACII 207 - Affective Computing and Intelligent Interaction. Berlin/Heidelberg, Springer: 203-217.

Halliday, Michael Alexander Kirkwood (1973): Explorations in the Functions of Language. London: Edward Arnold. 
Halliday, Michael Alexander Kirkwood (1978): Language as Social Semiotic: The Social Interpretation of Language and Meaning. London: Edward Arnold.

Hartley, Florence (1872): The Ladies' Book of Etiquette and a Manual of Politeness from a Gentler Time. Boston/New York: Lee and Shepard.

How to Shine in Society (1867): How to Shine in Society; or the Art of Conversation Containing ist Principles, Laws and General Usage in Modern Polite Society. Glasgow: Goerge Wattson.

Ide, Sachiko (1989): "Formal forms and discernment: Two neglected aspects of linguistic politeness". Multilingua 8: 223-248.

Janney, Richard Wayne/Arndt, Horst (1992): "Intracultural tact versus intercultural tact". In: Watts, Richard et al. (eds.): Politeness in Language: Studies in its History, Theory and Practice. Berlin/New York, Mouton de Gruyter: 21-41.

Kasper, Gabriele (1990): "Linguistic politeness: Current research issues". Journal of Pragmatics 14: 192-218.

Lakoff, Robin (1973): “The logic of politeness; or minding your p's and q's". Papers from the Ninth Regional Meeting of the Chicago Linguistic Society: 292-305.

Lakoff, Robin (1975): Language and woman's place. New York: Harper and Row.

Leech, Geoffrey Neil (1983): Principles of Politeness. London: Longman.

Leech, Geoffrey Neil (2014): The Pragmatics of Politeness. Oxford: Oxford University Press.

Locher, Miriam (2004): Power and Politeness in Action: Disagreement in Oral Communication. Berlin/New York: Mouton de Gruyter.

Locher, Miriam (2008): "Relational work, politeness and identity construction". In: Handbooks of applied linguistics: Communication competence, langauge and communication problems, practical solutions. Vol. 2: Handbook of interpersonal communication. Berlin/New York, Mouton de Gruyter: 509-540.

Mathesius, Vilém (1982): „O potenciálnosti jevů jazykových“. In: Mathesius, Vilém (ed.): Jazyk, kultura a slovesnost. Praha, Odeon: 9-28.

Meier, Ardith J. (1995): "Passages of politeness". Journal of Pragmatics 24: 381-392.

Minsky, Marvin (1975): “A Framework for representing knowledge”. In: Winston, Patrick H. (ed.): The psychology of computer vision. New York, McGraw-Hill: 211-277.

Ogiermann, Eva (2009): "Politeness and in-directness across cultures: A comparison of English, German, Polish and Russian requests". Journal of Politeness Research 5: 189-216.

Olshtain, Elite/Cohen, Andrew (1990): "The learning of complex speech act behaviour". TESL Canada Journal/Revue TESL du Canada 7/2: 45-65.

Scollon, Ron/Scollon, Suzanne (2001): Intercultural communication: A discourse approach. Oxford: Blackwell.

Shahrokhi, Mohsen/Bidabadi, Farinaz Shirani (2013): “An Overview of Politeness Theories: Current Status, Furute Orientations". American Journal of Linguistics 2/2: 17-27.

Sifianou, Maria (1992): Politeness Phenomena in England and Greece. A Cross-Cultural Perspective. Oxford: Clarendon Press.

Simpson, Paul (1997): Language through Literature. An Introduction. London/New York: Routledge.

Svartvik, Jan/Quirk, Randolph (eds.) (1980): A Corpus of English Conversation. Lund: CWK Gleerup. 
Spencer-Oatey, Helen (2000): "Rapport Management: A Framework for analysis". In: Spencer-Oatey, Helen (ed.): Culturally speaking: Managing rapport through talk across cultures. London/New York, Continuum.

Tanck, Sharyl (2004): "Speech act sets of refusal and complaint: A comparison of native and non-native English speakers' production”. TESOL Working Papers 4/2: 1-22.

Terkourafi, Marina (1999): "Frames for politeness: A case study". Pragmatics 9/1: 97-117.

Thomas, Jenny (1995): Meaning in Interaction. An Introduction to Pragmatics. London/New York: Longman.

Urbanová, Ludmila (1998): Semantic indeterminacy in authentic English conversation. Unpublished $\mathrm{PhD}$ dissertation, Masarykova univerzita.

Válková, Silvie (2004): Politeness as a Communicative Strategy and Language Manifestation (A Cross-cultural Perspective). Olomouc: Univerzita Palackého.

Válková, Silvie (2012): Regulating Discourse: Compliments and Discourse Signposts (English-Czech Interface). Saarbrücken: LAP.

Watts, Richard J. (1989): "Relevance and relational work: Linguistic politeness as politic behaviour". Multilingua 8: 131-166.

Watts, Richard J. (1992): "Linguistic politeness and politic verbal behaviour: Reconsidering claims for universality". In: Watts, Richard J. et al. (eds.): Politeness in Language: Studies in its History, Theory and Practice. Berlin, Mouton de Gruyter: 43-69.

Watts, Richard J. (2003): Politeness. Cambridge: Cambridge University Press. 